\title{
Dioniso en Platón: presencia y ausencia del dios de la máscara
}

\author{
Dionysus in Plato: Presence and Absence of the Mask God \\ David HeRnández de la Fuente \\ UNED, Madrid
}

RESUMEN. En este trabajo se propone una aproximación al uso filosófico del dios griego Dioniso en la obra de Platón, con especial referencia a la vertiente pedagógicopolítica del pensamiento platónico en la $R e$ pública y, sobre todo, en las Leyes. Se discuten brevemente los trabajos anteriores que han tratado esta cuestión, incluidos los dos más recientes que versan sobre las $L e$ yes y sobre la faceta filosófica de Dioniso, al hilo de una propuesta de lectura de las presencias y ausencias de Dioniso en Platón a través de tres dimensiones -el simposio, los misterios y la poesía con fines educativos- que convergen en la finalidad política reformista del filósofo ateniense.

Palabras clave: Platón; Dioniso; Teoría política griega; República; Leyes.

La utilización de la religión tradicional en la obra de Platón es uno de los aspectos más interesantes para comprender sus propuestas políticas y filosóficas. Entre las divinidades griegas más relevantes
ABSTRACT. In this paper we put forward an approach to the philosophical use of the Greek god Dionysus in Plato's work, with particular reference to the platonic pedagogical-political thought in the Republic and, above all, in the Laws. Previous studies that have addressed this issue, including the latest two dealing with the Laws and the philosophical aspects of Dionysus are briefly discussed while presenting a new reading of the presence and absence of Dionysus in Plato through three dimensions - the symposium, the mysteries and education-oriented poetry- converging on the reformist political purpose of the Athenian philosopher.

Key words: Plato; Dionysus; Greek Political Theory; Republic; Laws.

para la comunidad política, Dioniso ocupaba un papel ambivalente entre su faceta de dios público y teatral y de patrón de los misterios. Desde el punto de vista de la antigua religiosidad griega, Dioniso 
era sin lugar a dudas el más importante de todos los dioses por su interacción con los humanos y acaso el más interesante por la manera en que acercaba a los hombres a la categoría divina. Hijo de Zeus y de la mortal Sémele, que muere abrasada por el rayo al pedir imprudentemente a su divino amante que se le mostrara como dios, gestado por su padre entonces en su muslo, Dioniso es el dos veces nacido: la primera, del fuego de su padre, un viejo procedimiento mítico para otorgar inmortalidad, y la segunda, directamente del muslo del dios más poderoso. La esposa de Zeus, Hera, celosa contra el nuevo hijo bastardo de su marido, hará de Dioniso un dios enloquecido (mainomenos), que vagará por el mundo produciendo a su vez la locura y extrañamiento entre las mujeres con su cortejo de sátiros y ménades, mujeres enloquecidas (mainomenai), regentando sus rituales extáticos dionisíacos para ambos sexos, de bacchoi y bacchai, y dispensando sus dones, la danza y el vino, la capacidad de ser otro, la liminalidad y el paseo por el lado irracional, la conjunción, en definitiva, de las esferas divina, humana y animal en sus rituales tan importantes para la polis pero tan clara y excepcionalmente separados de la cotidianidad sociopolítica.

El dios del vino, el éxtasis y la embriaguez sacaba de sí mismos a los seres humanos, haciéndoles perder la conciencia de su condición, de las circunstancias que les rodeaban, y trasportándolos más allá de su realidad y de la experiencia humana. El éxtasis y la inspiración que implicaba la religión dionisíaca era exactamente esto, concebido como una forma de participar de lo divinidad mediante un cierto delirio que no era, por cierto, estrictamente resultante de la ingesta de alcohol u otras sustancias, sino que sin duda tenía otras causas psicológicas. El menadismo, como se ha venido en llamar desde A. Rapp, E. Robins o, más recientemente, E.R. Dodds, implica un éxtasis frenético, una extraordinaria fuerza física y un estado de percepción exaltado que eran de todo punto necesarios para los ritos dionisíacos, para la oreibasía, el sparagmós o la omophagia, si tales fueron en verdad algunas de las partes de estos rituales ${ }^{1}$. Las ménades o bacantes, mujeres del culto del dios ("Dionysos ist vorzugsweise der Frauen Gott", como ya veía Bachofen en Das Mutterrecht, 1861), eran capaces de alcanzar el delirio del dios, despedazar animales con sus manos desnudas y albergar al dios en lo más profundo, en una suerte de íntima conexión con las fuerzas divinas de la naturaleza. La vivencia de Dioniso era un éxtasis de música y de danza, una experiencia al mismo tiempo personal y colectiva, individual pero contagiosa: un fenómeno grupal y de espacios abiertos que tenía su repetición a pequeña escala privada en los misterios, desde el punto de vista religioso, y en algunos simposios, desde el punto de vista cívico.

Dioniso es "el que llega, el que viene de fuera", "der kommende Gott", como dijera el poeta Hölderlin, en una expresión que consagraría el estudioso del dionisimo W. Otto en su conocido libro de 1933 Dionysos: Mythos und Kultus: el que entra en el ámbito de la sociedad regulada por la norma, rompiendo la rutina y trastocándolo todo. Y de hecho, durante un largo periodo de tiempo su vieja figura 
mítica se perfilaba como la de un dios extranjero, tracio o frigio, con lo que sus mitos de muerte y resurrección se hacían pasar por no helénicos y la filología clásica alemana salvaba la recta racionalidad de los griegos (eso implicaba, en el fondo, la Psyche de Rohde). La relación del dionisismo con la inmortalidad, los misterios y los mitos chamánicos de ida y vuelta al otro mundo queda explícita en la leyenda órfica de Dioniso Zagreo, heredero del trono de Zeus y asesinado, a instancias de Hera, por los Titanes, que lo despedazan y se lo comen, tras lo que resucitará como el segundo Dioniso hijo de Sémele. Se decía, por otro lado (Rapp, 1872), que el menadismo violento era cosa del mito y nada histórico. Pero gracias al desciframiento en 1953 del Lineal B se vio que Dioniso estaba atestiguado en los documentos de Pilos, en el s. XIII a.C., posiblemente en relación con el vino. Por lo tanto, no era un dios llegado de fuera en la época arcaica, como podría parecer por su leyenda y habían sostenido algunos autores. También el menadismo quedó acreditado a lo largo del siglo XX gracias al descubrimiento de algunas inscripciones de época clásica, helenística o romana (en Mileto o Magnesia) que hablaban de ménades históricas ${ }^{2}$.

Dioniso es, en todo caso, un dios profundamente griego y, como tal, tenía implicaciones sociales y políticas importantes a las que no era insensible en absoluto la filosofía de Platón, ocupada por excelencia en la adecuación de la comunidad humana a las directrices del saber divino y el bien supremo. De hecho, el problema histórico de la religión dionisíaca siempre fue integrar en la comunidad humana a este dios afeminado, pseudo-extranjero, de la subversión y el extrañamiento temporales, la máscara utópica y áurea y, en cierto modo, de la política. Dioniso ayuda a todo el mundo a participar de lo divino en su éxtasis que va más allá de lo democrático e incluye a mujeres y esclavos. La cerámica ática de los siglos VI y V a.C. representa la conexión de Dioniso con la democracia con variadas referencias a su mito y culto. La ley religiosa y humana quedaba un tanto en suspenso durante los festivales dionisíacos, como las Antesterias, cuando volvía momentáneamente la sobreabundancia áurea y el igualitarismo a la tierra. El desenfreno del dionisismo se integraba estructuralmente en la construcción sociopolítica de la ciudad griega, representando el ciclo temporal en el que un cierto caos marginal religioso imperaba en el mundo entre periodos normales de orden. Para la civilización griega suponía un paréntesis ritual y catártico en el marco ciudadano en que se permitía ir más allá de los límites, tal y como sucedía en posteriores festividades como las Saturnales o el Carnaval.

La potencia de Dioniso en la cultura y la sociedad griega se mide de una doble manera: por su ausencia y su presencia. Como dios de la otredad y de la máscara, además de los numerosos festivales ciudadanos en su honor, de las Antesterias a las Dionisias Rurales y Urbanas, su mención o el silencio sobre su figura es la marca que nos indica su acción sobre la realidad griega: desde que Homero cita al dios como gozo para los mortales a su escueta presencia en Hesíodo o hasta que en las Bacantes Eurípides dejó entrever algo de los misterios que tanta aceptación tuvieron en la Grecia clásica. 
Como símbolo de vida indestructible, glosando la célebre obra de Kerényi (1976), en la literatura griega, como el hermano de Apolo que reina alternativamente en Delfos, Dioniso aparece y desaparece en la cultura griega, a veces visible, a veces subterráneo, pero siempre dejando una huella de su poder, como se mostrará en lo que sigue para el caso de Platón. No en vano, el teatro pertenece a los dominios de este dios de la máscara, el engaño, la locura y la fícción.

La problemática de Dioniso reside en su condicion ambivalente entre lo visible y lo invisible, los márgenes y el centro, lo que también se confirma desde el comienzo de su recepción moderna con $E l$ Nacimiento de la Tragedia de Nietzsche en 1872. El dionisismo ofrece resistencia a todas las racionalizaciones, antiguas, decimonónicas y modernas, por la polifonía de manifestaciones literarias, iconográficas y filosóficas que ha implicado desde su aparición en época histórica. Aun hoy representa el intento inasible y siempre en progreso de comprender al hombre moderno. Desde Nietzsche a esta parte, toda época de cambio ha conllevado una nueva interpretación del dionisismo: Walter Pater en la época victoriana, los ritualistas de Cambridge en la Primera Guerra Mundial, Walter Otto antes del nazismo, Jeanmaire en la posguerra francesa, Kerényi en la psicología jungiana, Girard (1972), Detienne (1977) y la escuela de París en el 68 francés... hasta llegar al Dioniso de Richard Seaford (2006), con una síntesis para el uso de la postmodernidad. Pero el examen filosófico o antropológico de cuanto implica esta divinidad y su recepción en lo moderno excede con mucho los límites de esta contribución.
Nuestro propósito es presentar un panorama de la presencia de Dioniso en su doble función de dios público y teatral y de patrón de los misterios en los diálogos de Platón. Nos proponemos una breve indagación acerca de la relevancia del dios de la máscara en los diálogos de Platón, examinando algunas apariciones u omisiones clave en la obra del filósofo ateniense, para terminar en el libro II de las Leyes, en el que se establecen las reglas para el consumo del vino, don de Dioniso, y se honra al dios dedicándole un coro de notable simbolismo para el preámbulo pedagógico de las leyes de la ciudad ideal de Magnesia. Ante todo hay que decir que Dioniso es en Platón mucho más que el dios griego del vino y la fertilidad. En primer lugar, desempeña un papel de gran importancia como símbolo de la naturaleza salvaje. En segundo lugar, no es sólo patrón del éxtasis religioso y el teatro, sino también un dios que conoce bien la muerte y el otro lado. Dioniso puede morir y renacer, como cuenta el mito órfico de Dioniso Zagreo, y muestra a los hombres en sus misterios lo que le sucede al alma al otro lado. Por lo tanto, es enormemente relevante tanto para la poética de Platón como para su psicología y escatología. En tercer lugar, hay que mencionar la función político-pedagógica de Dioniso como dios patrón del simposio, del beber juntos entre hombres. Por desgracia, la presencia de Dioniso y sus ritos en Platón, en su poética, en su teoría del alma y en sus propuestas político-pedagógicas, desde mi punto de vista aún no ha sido suficientemente investigada, pese a algunos tratamientos parciales de los temas y elementos dionisíacos en la obra del filósofo ateniense ${ }^{3}$. 
Esta contribución sugiere un concepto diferente de Dioniso en Platón, haciendo hincapié en la importancia de un dios arcaico de la fertilidad para el proyecto sociopolítico del filósofo en conjunto $\mathrm{y}$, sobre todo, en su última obra, para la que proponemos un estudio diferenciado. El estudio de presencia dionisíaca en las Leyes puede revelar algunas claves del papel de la religión tradicional en Platón. En su faceta de dios de un mundo utópico de la edad de oro, que regresa regularmente a los hombres gracias a sus festividades, pero sobre todo al vino y a la embriaguez, Dioniso va a encarnar en Platón no solo a la divinidad del culto mistérico que conoce los secretos de las transformaciones de la naturaleza, sino también a una figura políticamente útil, que resulta indispensable para la cohesión de la sociedad. A pesar del aparente descrédito del mundo dionisíaco (tragedia y embriaguez) para la vida filosófica que puede verse en la República ${ }^{4}$, las Leyes presentan una visión evolucionada de la religión de Dioniso. Esto sucede especialmente en el segundo libro del diálogo, donde el anónimo ateniense -un alter ego del propio Platón-, desarrolla un largo discurso acerca de la utilidad del vino, la embriaguez, los simposios y el coro de Dioniso. Este punto ha causado cierta confusión en los estudiosos, sobre todo en comparación con la República. Sin embargo, otros intérpretes han buscado en esta aparente contradicción una metáfora psicológica, teatral, política o filosófica, como Elizabeth Belfiore, Michael A. Rinella o Giovanni Panno. En todo caso, intentaremos demostrar que las presencias y ausencias de Dioniso en Platón dicen mucho del uso de los dioses tradicionales en los pro- yectos político-pedagógicos del filósofo y muestran la presencia de una cierta simbiosis arcaizante entre política y religión en el último diálogo de Platón. A pesar de la opinión de Jeanmaire, quien describió en 1951 a Dioniso ${ }^{5}$ como un dios apolítico, su culto desempeñó siempre un imporante papel en la cohesión de la ciudad clásica. En muchos sistemas políticos, la sisitía o "cena común", y el simposio, literalmente, el "beber común”, eran instituciones político-sociales de gran importancia para la vida social ciudadana. Su origen mítico se asocia en todo caso con el cortejo y fiestas de Dioniso, por un lado, y con la utopía de la Edad de Oro, por otro, pues ambos mitos presentan el alimento común y la bebida abundante, así como la libertad y la felicidad, como partes fundamentales. También en la legislación de la última ciudad platónica se pueden hallar restos de instituciones tradicionales dorias, como la sisitía o los coros públicos, por las que Platón muestra un interés inusual. En este sentido trataremos de mostrar a Dioniso como dios con significación política en Platón.

Pero veamos cuáles son los tres principales grupos conceptuales en los que aparece mencionado el dios por el filósofo: en primer lugar, se asocia a Dioniso con el simposio, en segundo lugar con los misterios y en tercer lugar con la poesía. Durante el Banquete de Platón se esbozan en una reunión dionisíaca, como es sabido, varios discursos poéticos sobre el amor. No es de extrañar que la competición entre los diversos oradores comience con una invocación al dios, que aparece como un árbitro de los distintos discursos sobre el amor que se presentarán (175d-176a). 


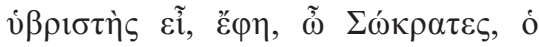

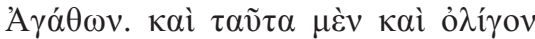

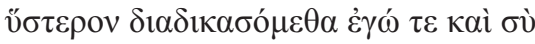

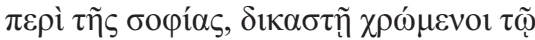

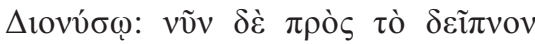
$\pi \rho \tilde{\omega} \tau \alpha \tau \rho \varepsilon ́ \pi o v$.

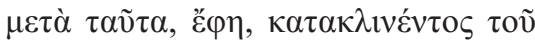

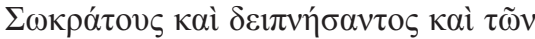

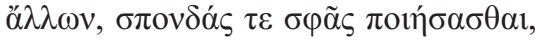

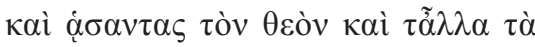

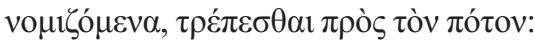
Eres un exagerado, Sócrates, contestó Agatón. Más este litigio sobre la sabiduría lo resolveremos tú y yo un poco más tarde, y Dioniso será nuestro juez. Ahora, en cambio, presta atención primero a la comida.

A continuación -siguió contándome Aristodemo-, después que Sócrates se hubo reclinado y comieron él y los demás, hicieron libaciones $\mathrm{y}$, tras haber cantado a la divinidad y haber hecho las otras cosas de costumbre, se dedicaron a la bebida. ${ }^{6}$

Dioniso aparece como el patrón del simposio, con su máscara tragicómica, y se le canta un himno de elogio antes de que los participantes empiecen a beber. La invocación al dios del vino en este punto inicial del Banquete ha llevado a pensar a algunos estudiosos en una utilización consciente de materiales del culto dionisíaco en este diá$\log 0^{7}$. Este Dioniso bajo cuya advocación se celebra el banquete platónico es mucho más, obviamente, que el dios del vino, y tiene matices que lo aproximan al Eros más poderoso, a las divinidades del orfismo y al simbolismo cosmogónico, como ha señalado Anderson ${ }^{8}$. Este autor, en su comentario al diálogo, propone estudiar a cada per- sonaje bajo una "máscara" dionisíaca, sin perder nunca de vista que Dioniso es el dios del teatro, y leer los discursos del amor de cada cual bajo las diversas atribuciones que tiene el dios, ya sean festivas y libertarias, ya cosmogónicas y mistéricas. Pero no olvidemos, a ese respecto, que Dioniso preside el acto de beber entre los griegos. En el desarrollo del simposio platónico per se, es decir, del proceso del beber juntos, hay participantes más o menos moderados, hasta la llegada de Alcibíades, notoriamente borracho. El joven terrible elogia a Sócrates precisamente por su moderación en usar los dones de Dioniso (217 a). Ciertamente Sócrates, como un lider del simposio, es capaz de sustraerse al poder embriagador de Dioniso ${ }^{9}$. Parece que el filósofo debe controlar la embriaguez, al igual que el líder de los participantes en el simposio debe llevar las almas a un puerto seguro. Después de todos los discursos sobre el amor (Pausanias, Aristófanes, etc.) el verdadero amor filosófico se describe en detalle en la conversación de Sócrates y Diotima como una especie de iniciación mística.

La primera mención a Dioniso del Banquete, por parte de Agatón, se entiende bien por haber recibido un premio por su tragedia, que se sitúa bajo la advocación de Dioniso, y alude a otro tratamiento favorable con el dios como juez, en este caso, en el simposio. El efecto del vino, don de Dioniso, hace parecer al participante en esta fiesta un inspirado por el dios, a la manera paralela en que Apolo inspira a su Pitia o a sus poetas. Pero esta vez la inspiración es filosófica y conduce a la verdad, como Alcibíades evoca en el pasaje citado, en un camino que recorren los participantes en compañía de Sócrates, un buen guía para el simposio. Dioniso re- 
corre el banquete, según la interpretación de Anderson, en ausencias y presencias, pues se le invoca por una parte pero, por otra, hay participantes que pretenden dejarle de lado, como Erixímaco, lo que acaso queda simbolizado en su desprecio a la flautista (176e). La ambivalencia entre un dionisismo festivo y otro más místico se nota también en los distintos grados de embriaguez, como el de Alcibíades; en todo caso, y cito a Anderson (mi traducción), "Platón parece sugerir que Sócrates es una criatura de Dioniso" (Anderson 1993, 11), como se ve claramente en su identificación con Sileno.

En este sentido, también se debe llamar la atención sobre la presencia de Dioniso en Platón como patrono de la iniciación religiosa en los misterios y como inspirador de un cierto entusiasmo místico, como se lee en el Fedro. Este diálogo entre Sócrates y Fedro enlaza temáticamente con el Simposio, pues en él se recogen fragmentos de diversos oradores y poetas sobre el proceso del enamoramiento, evocados por Fedro, mientras que Sócrates pronuncia dos discursos sobre el amor y el alma. El destino del alma y su caída a la Tierra son ilustrados por el conocido mito del carro celestial. Cuando el alma ve algo hermoso en la tierra recuerda su vivencia anterior en el cuerpo en un proceso de enamoramiento que tiene algo de "locura" (265a-b).

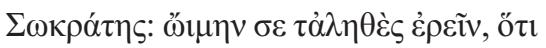

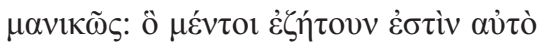

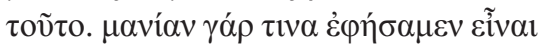
$\tau$

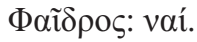

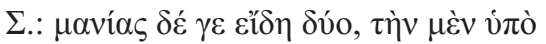

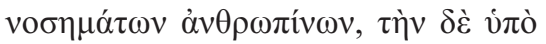

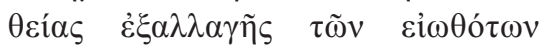

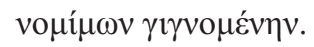

$\Phi .: \pi \alpha ́ v v \gamma \varepsilon$.

$\Sigma .: \tau \tilde{\eta} \varsigma \delta \varepsilon \dot{\varepsilon} \theta \varepsilon i ́ \alpha \varsigma \tau \varepsilon \tau \tau \alpha ́ \rho \omega \nu \theta \varepsilon \tilde{\omega} \nu \tau \varepsilon \dot{\tau} \tau \alpha \rho \alpha$

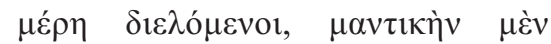

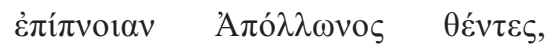

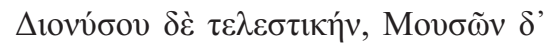

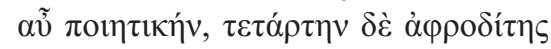

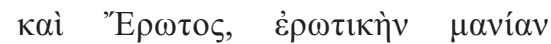

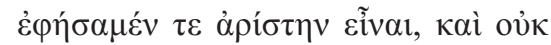

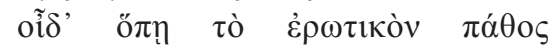

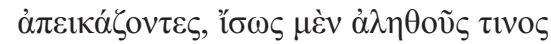

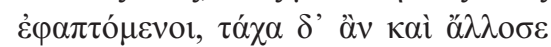
$\pi \alpha \rho \alpha \varphi \varepsilon \rho o ́ \mu \varepsilon v o 1, \quad \kappa \varepsilon \rho \alpha ́ \sigma \alpha \nu \tau \varepsilon \varsigma$ ov̉

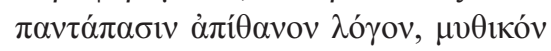
$\tau \imath v \alpha$ ű $\mu v o v \pi \rho \circ \sigma \varepsilon \pi \alpha i ́ \sigma \alpha \mu \varepsilon v \mu \varepsilon \tau \rho i ́ \omega \varsigma \tau \varepsilon$

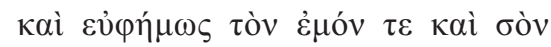

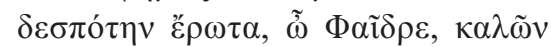

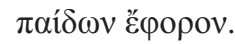

S.: Pienso que ibas a decir la palabra justa: maniáticamente. Porque dijimos que el amor era como una locura, una manía, ¿o no?

F.: Sí.

S.: Pero hay dos formas de locura; una, debida a enfermedades humanas, y otra que tiene lugar por un cambio que hace la divinidad en los usos establecidos. F.: Así es.

S.: En la divina, distinguíamos cuatro partes, correspondientes a cuatro divinidades, asignando a Apolo la inspiración profética, a Dioniso la mística, a las Musas la poética, y la cuarta, la locura erótica, que dijimos ser la más excelsa, a Afrodita y a Eros. Y no sé de qué modo, intentando representar la pasión erótica, alcanzamos, tal vez, alguna verdad, $\mathrm{y}$, tal vez, también nos desviamos a algún otro sitio. Amasando un discurso no totalmente carente de persuasión, hemos llegado, sin em- 
bargo, a entonar, comedida y devotamente, un cierto himno mítico a mi señor y el tuyo, el Amor, oh Fedro, protector de los bellos muchachos. ${ }^{10}$

En la célebre digresión sobre los tipos de locura divina, a Dioniso se le adscribe la segunda, es decir, la telestiké manía o locura de los misterios, un entusiasmo religioso paralelo a la locura adivinatoria de Apolo, la poética de las Musas y la amorosa de Eros. Numerosos autores entre ellos G. Reale- han insistido en los paralelos de la descripción del amor con el vocabulario de las iniciaciones mistéricas y es un lugar común relacionar la manía profética y la poética. Pero a propósito de himnos y musas, Dioniso es evocado también en Platón como el dios de un cierto tipo de entusiasmo poético y musical. Los poetas cantan sus himnos de una manera inspirada e irracional, casi como las ménades poseídas por Dioniso o como la inspirada Pitia de Apolo. Con esto en mente Sócrates habla con una cierta ironía al poeta Ión en el diálogo del mismo nombre de Platón acerca del carácter dionisíaco de cierta poesía y de ciertos poetas (534a-c):

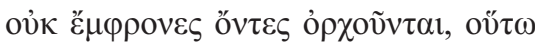

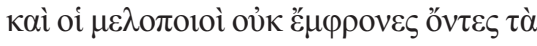

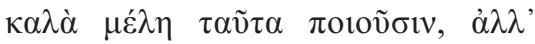

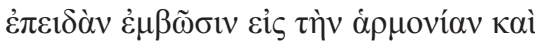

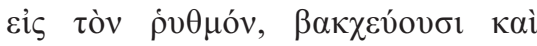

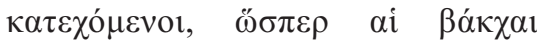

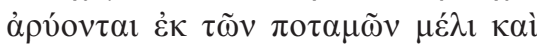

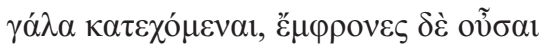

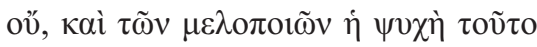

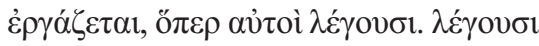

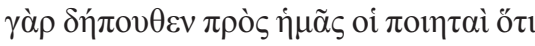

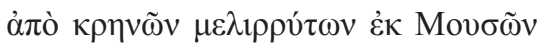

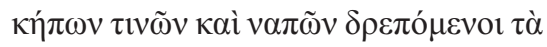

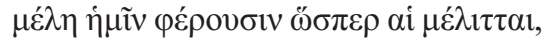

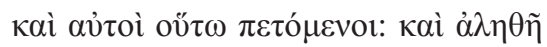

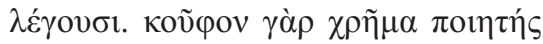

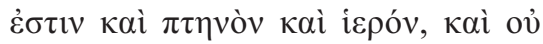

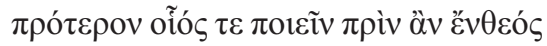

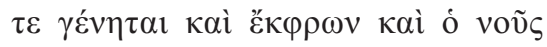

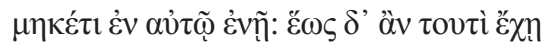

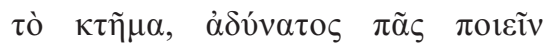

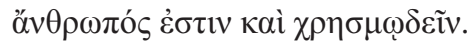

Esto mismo le ocurre a los buenos líri$\cos$, e igual que los que caen en el delirio de los Coribantes no están en sus cabales al bailar, así también los poetas líricos hacen sus bellas composiciones no cuando están serenos, sino cuando penetran en las regiones de la armonía y el ritmo poseídos por Baco, y, lo mismo que las bacantes sacan de los ríos, en su arrobamiento, miel y leche, cosa que no les ocurre serenas, de la misma manera trabaja el ánimo de los poetas, según lo que ellos mismos dicen. Porque son ellos, por cierto, los poetas, quienes nos hablan de que, como las abejas, liban los cantos que nos ofrecen de las fuentes melifluas que hay en ciertos jardines y sotos de las musas, y que revolotean también como ellas. Y es verdad lo que dicen. Porque es una cosa leve, alada y sagrada el poeta, y no está en condiciones de poetizar antes de que esté endiosado, demente y no habite ya más en él la inteligencia. Mientras posea este don, le es imposible al hombre poetizar y profetizar. ${ }^{11}$

Es obvio que Sócrates argumenta que la poesía no se basa en el conocimiento, sino que es un don divino o la inspiración 
por la que el poeta habla en una suerte de ebriedad. Como un imán, que atrae a un anillo de hierro magnetizado, el poeta está unido a la divinidad y el público en una especie de correa de transmisión y de atracción, según el conocido símil de este diálogo. Así, Platón expresa su concepción crítica de la poesía tradicional ${ }^{12}$ que es luego ampliada en la República. La poesía trágica es criticada por el filósofo en el libro V (475 d), en referencia a los festivales de teatro, pues las tragedias -que, no olvidemos, se representaban en las fiestas dionisíacas y estaban bajo la protección del dios de la máscara-, alejaban a los hombres de la participación en la vida filosófica. Explica el filósofo en el libro VIII (568) la falsa felicidad y sabiduría del tirano refiriéndose con ironía al trágico griego más popular, Eurípides, autor de la única tragedia de tema dionisíaco conservada. En el libro X se proclama a Homero es el gran maestro de los poetas de tragedia (595C), pero sorprendentemente no se menciona en ningún momento al legendario patrono de este arte, el dios Dioniso. Hay un silencio que parece estar relacionado con la famosa censura de los poetas en la República. Según Pierre Vicaire (1958), la ausencia de Dioniso en la República es una táctica para menoscabar el teatro y desvincularlo de su adscripción divina y de toda relación con los festivales del dios de la máscara. Otras valoraciones de la poesía, por otra parte, en los libros II, III y X vuelven a silenciar la inspiración divina del arte poético-teatral ${ }^{13}$, laguna importante frente a lo visto en el Fedro o el Ión. Pero no todos los géneros de la poesía son tan duramente criticados en la República de Platón (394b-e):

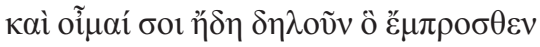

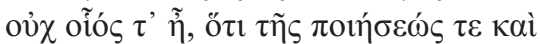

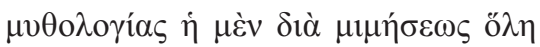

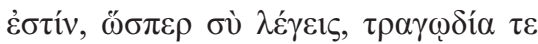
$\kappa \alpha i ̀ ~ \kappa \omega \mu \omega \delta i ́ \alpha, \dot{\eta} \delta \grave{\varepsilon} \delta \imath^{\prime} \dot{\alpha} \pi \alpha \gamma \gamma \varepsilon \lambda i \alpha \varsigma$

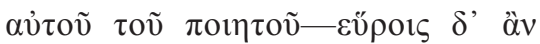

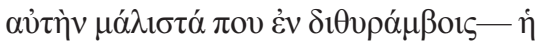

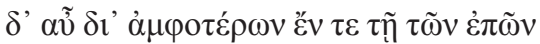

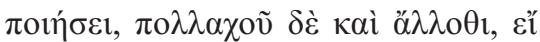
$\mu \mathrm{ol} \mu \alpha v \theta \alpha \dot{v \varepsilon \varepsilon s}$.

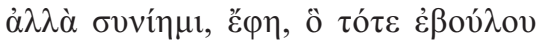
$\lambda \varepsilon \dot{\gamma \varepsilon i v . ~}$

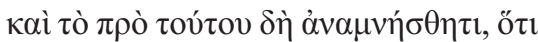

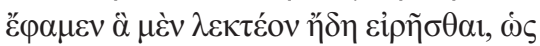

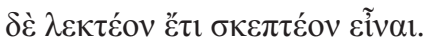

$\grave{\alpha} \lambda \lambda \grave{\alpha} \mu \varepsilon \dot{\varepsilon} \mu \nu \eta \mu \alpha \mathrm{l}$.

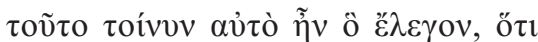

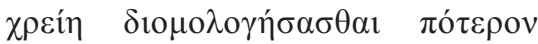

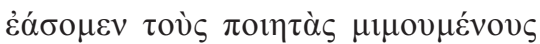

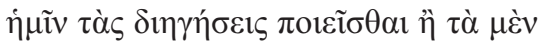

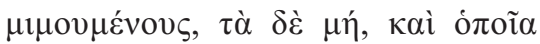

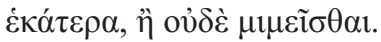

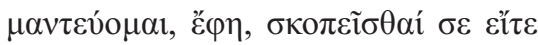
$\pi \alpha \rho \alpha \delta \varepsilon \xi o ́ \mu \varepsilon \theta \alpha \quad \tau \rho \alpha \gamma \omega \delta i ́ \alpha \nu \quad \tau \varepsilon \quad \kappa \alpha i$

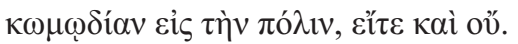

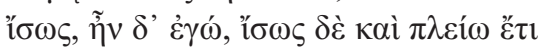

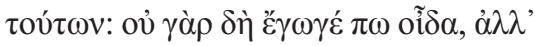

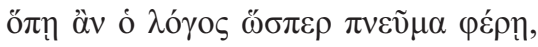

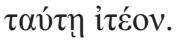

-Tu suposición ha sido muy correcta, y pienso que ya te he aclarado aquello que antes no fui capaz, a saber, que una parte de la composición poética y del relato de mitos se hace toda ella por medio de la imitación (como tú dices, la tragedia y la comedia), otra parte por medio de las informaciones del propio poeta (este tipo puedes encontrarlo especialmente, creo, en los ditirambos), y a su vez una tercera por medio de ambos procedimientos, en la poesía épica 
y en muchos otros tipos de composiciones, si me entiendes.

-Me doy cuenta de lo que entonces querías decir-replicó.

-Acuérdate también de lo que decíamos antes: afirmábamos que ya habíamos hablado sobre lo que debe decirse, pero que aún debíamos examinar cómo hay que decirlo.

-Me acuerdo.

-Pues bien, con esto yo quería decir que debíamos ponernos de acuerdo sobre si vamos a permitir que los poetas nos hagan las narraciones imitando, o bien imitando unas veces y otras no (y en qué casos sí y en cuáles no), o bien tampoco les vamos a permitir que imiten.

-Adivino -dijo- que estás examinando si vamos a aceptar o no la tragedia y la comedia en nuestra ciudad.

-Quizá, y también quizá asuntos incluso más importantes que esos. Ni siquiera yo mismo lo sé todavía; mas por donde nos lleven nuestras palabras, como un soplo de viento, por ahí hemos de ir. ${ }^{14}$

En efecto, se diría que hay un tipo de poema arcaico y, esta vez sí, relacionado con la tradición religiosa, que se salva de la criba por ser tradicional, inmutable y digno de imitación y enseñanza a las nuevas generaciones de ciudadanos. La tragedia y la comedia parecen objetables al severo filósofo, ya que son esencialmente artes miméticas, es decir, que imitan las acciones humanas (III 394c). Sin embargo, hay un balance más positivo para otros géneros como la épica, un género mixto entre la narración y el teatro, o la poesía lírica que, de acuerdo con este pasaje, es pura narración sin mímesis. Pero sorprendentemente, la referencia a la lírica se obra mediante el término técnico "ditirambo". Por supuesto, el ditirambo es un género de la poesía lírica coral que se dedica a Dioniso, así como el Peán es el himno que pertenece por excelencia a Apolo. El ditirambo era cantado y bailado en honor de Dioniso en sus festivales, como las fiestas Dionisias y, según afirma Aristóteles en sus Problemas, era inicialmente un género puramente narrativo, que más tarde se volvió mimético ${ }^{15}$. Este filósofo, en su Poética, hace derivar también del ditirambo y de la poesía dionisíaca arcaica toda la tragedia ateniense ${ }^{16}$. Por lo tanto, en principio, parece muy destacable que este arcaico género lírico dionisíaco, considerado origen de la tragedia, sea ensalzado en la República (394c) como el ejemplo más conspicuo de la poesía aceptable. Platón ni siquiera ha nombrado Dioniso al hablar de la tragedia o del ditirambo, pero su presencia se intuye tácitamente ya aquí al mencionar el género dedicado al dios (como ocurriría con Apolo si se hubiera puesto de ejemplo el Peán). Tal vez, en comparación con la tragedia, la ventaja del ditirambo sea su pureza incontaminada por la democracia ateniense, si se tiene en cuenta que en el sistema político de Atenas la tragedia tenía una importante función pedagógica. Platón opta aquí por mencionar el ditirambo, la forma arcaica de la poesía dionisíaca, característica de los viejos tiempos, cuando la democracia no lo había estropeado todo, por así decir. Arcaico y enmascarado, este Dioniso lírico es la presencia intuida en la República y prepara- 
toria, a mi ver, del desenmascaramiento del dios en las Leyes.

En este último diálogo platónico el filósofo elabora un último proyecto de ciudad ideal, que se encuentra muy cerca de la tradición religiosa y mitológica y que en ocasiones recuerda a la historia temprana del desarrollo político-religioso de la polis con las reformas de Solón y Clístenes. A pesar de la visión tradicional de los críticos que han visto a las Leyes como una obra de compromiso con la realidad, el mito y la religión son especialmente relevantes en ellas. En las Leyes, como se anticipaba, la posición de Dioniso es muy diferente porque el dios está explícitamente presente en el libro segundo. Los tres aspectos de su personalidad que se citaban anteriormente -simposio, misterios y poesía- aparecen juntos en las Leyes y se asocian indisolublemente con el objetivo de establecer una sociedad solidaria y educar a sus miembros para la mejor convivencia.

Veamos primero el tema del simposio, que se asocia a la indagación en las instituciones tradicionales que puedan ser beneficiosas para la ciudad ideal y a la educación más apropiada para los ciudadanos. El primer libro contiene un resumen de la investigación en torno a la ley y a sus orígenes religiosos. La ciudad ideal de Platón parece fundarse a partir de unas reflexiones sobre ciertos modelos constitucionales dóricos, Creta y Esparta, que se ponen en discusión con la valoración de sus objetivos, sus logros y sus defectos. Desde el principio del diálogo se pone especial énfasis en la relacion de la ley con lo divino a través de personajes excepcionales, legisladores como Minos de Cnoso o Licurgo de Esparta. Las referencias míticas en este comienzo del diálogo -los libros I y II- son muy destacables e incluyen al profeta Epiménides y al dios Dioniso. Hay que reparar en que aún no ha comenzado la legislación propiamente dicha que propone Platón para la ciudad de Magnesia, sino que nos hallamos en una suerte de preámbulo inspirador, en el que se dan líneas generales para lo que vendrá después, las leyes detalladas para la vida en común. Ya en el diálogo pseudoplatónico Minos (319 e-320e) se apunta que este mítico rey, hijo de Zeus y legislador, que recibía la ley divina directamente de su padre en experiencias iniciáticas en una gruta, legisló sobre la embriaguez y reguló el simposio de tal forma que nadie se embriagara demasiado. En estos modelos dóricos de origen divino, por supuesto, el banquete común es una institución muy importante ${ }^{17}$. En la legislación legendaria de Creta y Esparta, que viene respectivamente de Zeus y Apolo, Platón encuentra ciertos motivos previos para algunas instituciones que han de inspirar la ciudad de Magnesia. Pero en seguida se llega a la cuestión poco doria del simposio, cuando se analizan las facilidades para el ejercicio de la virtud, el coraje y la fortaleza en Esparta. Entonces se llega a la pregunta de si es admisible en una sociedad ideal el disfrute del vino y la embriaguez. Aquí el extranjero ateniense contradice la tradición doria y sostiene la que ausencia absoluta de embriaguez en Esparta es algo negativo (674d). Se propone entonces un uso controlado del vino, que tiene por objetivo la educación de los ciudadanos en la virtud y el coraje. Los simposios requieren un líder sobrio que los hará extremadamente 
útiles para la enseñanza de la virtud. Al final del libro el don de Dioniso se alaba como un medio de prueba para el dominio de uno mismo.

En segundo lugar, en cuanto a los cultos de los misterios, Platón es consciente de que el significado de los misterios divinos tiene una implicación política y utópica importante, como manera de lograr la felicidad más cercana a la edad de oro en esta nuestra edad de hierro. Aunque la felicidad en el más allá descrita por los cultos órfico-dionisíacos como una embriaguez perpetua y una abundancia de alimentos aparece mencionada críticamente en la República (363cd), las Leyes presentan otro panorama. En efecto, se afirma explícitamente que el vino es un regalo de Dioniso para ayudar a las personas y para aumentar el éxtasis de la danza de los misterios $(653 \mathrm{c}-\mathrm{d})^{18}$, y todo ello para bien de los hombres, para corrección de su vida y educación de su alma en las fiestas divinas:

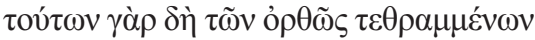

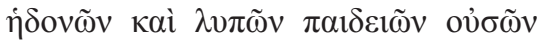

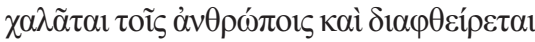

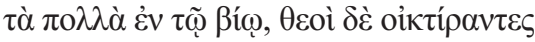

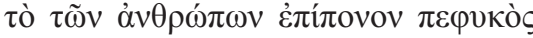

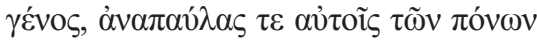

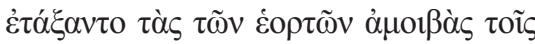

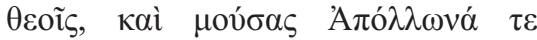

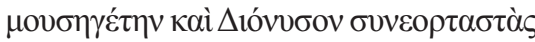

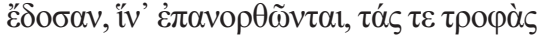

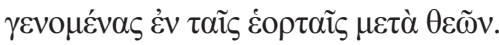
Muchos de los placeres y dolores correctamente formados, que son la educación, se relajan y destruyen en el transcurso de la vida de los hombres. Y los dioses, compadecidos del género humano, que por naturaleza ha de sufrir, dispusieron para los hombres un alivio de sus fatigas en las fiestas alternas en honor a los dioses, y también les concedieron a las musas, Apolo, el conductor de las musas, y Dioniso para que festejaran con ellos, de forma que se restaurase la crianza que se producía en las fiestas junto a los dioses. ${ }^{19}$

Si como parece los cultos mistéricos han influido tan fuertemente la doctrina platónica del alma, aquí se reconoce la influencia de este mitema del regreso temporal de la edad de oro gracias a los misterios de Dioniso de forma clara y políticamente muy relevante, en esta suerte de preámbulo a las leyes de la ciudad ideal de Platón. El viejo mito de las edades de Hesíodo y su variante mistérica de las islas de los bienaventurados que aparece en Píndaro y otros autores, se actualiza en la polis y vuelve a los hombres gracias a la compasión de los dioses y a los dones del más cercano a los humanos de todos ellos: Dioniso. Este mito de la edad de oro es de interés para el pensamiento utópico por la idea de su retorno prometido, ya circular, ya periódico. En cuanto al primero, los textos sagrados del orfismo también hablaron de la posibilidad de alcanzar la edad de oro paradisíaca para los justos bajo el gobierno del viejo Crono en un más allá utópico, aunque Dioniso parece regir ese mundo áureo del más allá en sus regresos periódicos al nuestro. ${ }^{20}$

Desde sus primeros diálogos Platón muestra conocer estas ideas religiosas sobre el más allá de los bienaventurados, como en el Gorgias (523) o en la República (363C). Pero, en segundo lugar, esta edad de oro tiene una vertiente de retorno 
cíclico que se debe a Dioniso, dios de la vegetación, que la recrea en la ciudad gracias a sus fiestas, sus coros y sus dones espontáneos como el vino, miel, leche y todo tipo de vegetales exuberantes. ${ }^{21} \mathrm{Pla}$ tón conoce también este aspecto de los ritos dionisíacos de las bacantes, como en el citado pasaje del Ión ${ }^{22}$, y en qué forma regresan para traer otra edad de oro a los mortales, como en las Leyes, que enlazan la edad de oro y la abundancia de Dioniso (713b-e). Entonces, lo que habría que hacer sería "imitar por todos los medios la vida llamada de la época de Cronos" ${ }^{23}$ cuando los hombres vivían en ciudades perfectas y bajo la égida de gobernantes divinos (713d), entre el ocio, el placer y una abundancia que no sólo era material y alimenticia, sino también de justicia (713 e).

Por último, la poesía también aparece en el Dioniso de las Leyes, cuyo libro II se refiere a la importancia del vino y la música para la educación del alma, una discusión dionisíaca que se sitúa antes de que empiece la legislación de la ciudad propiamente dicha, como una especie de preludio simbólico. También las Leyes se oponen al libre desarrollo de la función poética, salvo si se somete a una estricta censura ( $817 d)$, pues el poder de la poesía es enorme y los legisladores han de proteger a la población regulándola según la ley y la justicia. Llama la atención, no obstante, que las palabras que se dirigen a los poetas son respetuosas y recuerdan al Ión y a la consideración de la locura divina de los poetas en el Fedro: se les llama "hombres divinos", "los mejores extranjeros" y el legislador les considera en cierto modo rivales: "También nosotros somos poetas trágicos, y nuestra tragedia
(...) es la mejor y más noble. Tanto vosotros como nosotros somos poetas... rivales y antagonistas en el más noble de los dramas, que solo la verdadera ley puede hacer perfecto." (817 b). La ciudad debe estar bajo el hechizo de la ley pues esta misma parece poseer los caracteres de la poesía: se comparan los preámbulos de la ley con preludios poéticos: "medidas de la lírica y la música y de todo tipo deben tener preludios elaborados con el mayor cuidado “ (722e) y también las leyes deben ser precedidas por este tipo de preludios, del que el episodio del coro de Dioniso es un ejemplo, no en vano nomos es melodía y ley, y así se juega con los dos sentidos en la obra.

La presencia del culto a Dioniso es muy notable en las Leyes y sobre todo en el libro II, pues se ve positivamente la contribución del simposio dionisíaco para la educación del alma. Según E. Belfiore esta valoración es de cierta manera revolucionaria para la tradicional doctrina platónica del alma, o por lo menos una contradicción con el tratamiento de Dioniso de la República, donde la embriaguez es condenada $^{24}$. El vino permite un tipo de formación en la que el alma aprende a resistir los placeres, lo que a veces es más complicado que aguantar el dolor. Con este propósito, el extranjero ateniense propone establecer tres coros diferentes para educar a los ciudadanos de diversas edades (Leyes $665 \mathrm{ab})$ :

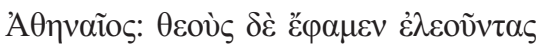

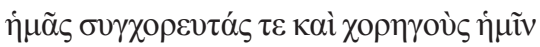

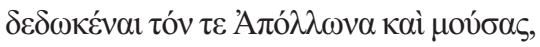

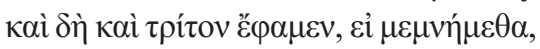
$\Delta$ tóvvoov.

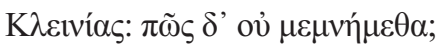




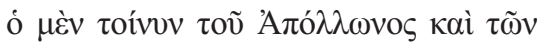

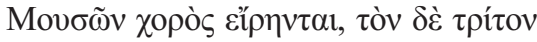

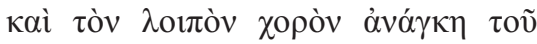

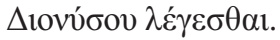

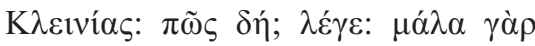

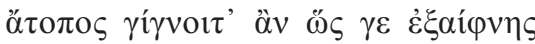

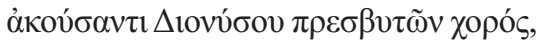

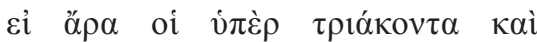

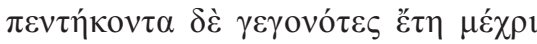

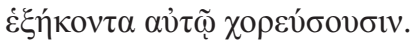

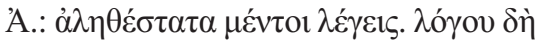

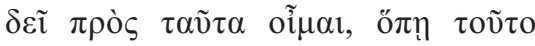

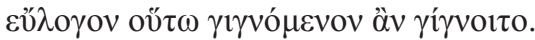

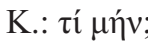

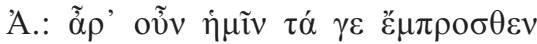
ó $\mu \mathrm{o} \lambda \mathrm{o} \gamma \varepsilon \tilde{\imath} \tau \alpha$;

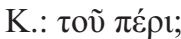

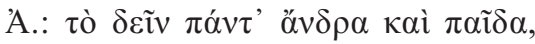

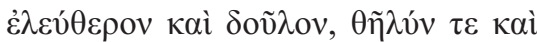

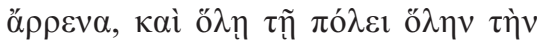

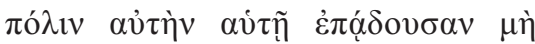

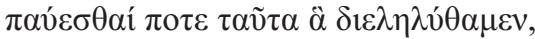

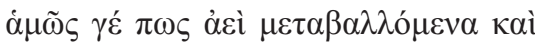

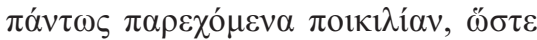

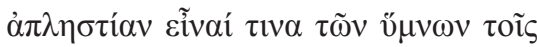

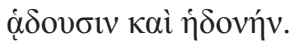

Decíamos que como los dioses se compadecieron de nosotros nos dieron como compañeros de baile y jefes de danzas a Apolo y las Musas y en tercer lugar, si recodamos bien, a Dioniso.

Cl. ¿Cómo no íbamos a recordarlo?

At. Así pues se ha hablado del coro de Apolo y del de las Musas, pero se debe hablar por fuerza también del tercer coro restante, el de Dioniso.

Cl. ¿Y cómo? Habla, pues sería harto insólito, al menos para el que escucha de repente, un coro de ancianos bajo el mando de Dioniso, si han de bailar los que tienen más de treinta y cincuenta años hasta incluso los de sesenta.

At. Dices toda la verdad, pero es necesario, según creo, argumentar cómo podría hacerse esto de forma razonable.

Cl. Ciertamente.

At. ¿Acaso no estamos de acuerdo en lo anterior?

Cl. ¿A qué te refieres?

At. A que conviene que todo hombre y niño, libre y esclavo, mujer y varón, $\mathrm{y}$ la ciudad entera no deje nunca de entonar encantos para sí mismos en todo momento sobre las cosas que hemos explicado, cambiándolas siempre de algún modo y dándoles cierta variedad en lo posible, de forma que se genere en los que cantan unas ganas insaciables de himnos y un placer en ellos.

El más importante es el coro de Dioniso, para el que se establecen diferentes reglas, en cuanto a cómo beber, a cómo cantar y a qué cantar, que ha de ser lo mejor del arte poético. El tema de la educación fue siempre la principal preocupación del filósofo y en el caso del control del vino y el coro de Dioniso, podemos confirmar un uso político del culto a Dioniso, pese a ser descrito a menudo erróneamente como dios apolítico ${ }^{25}$. En comparación con la República o con otro pasaje de las Leyes (815c-d), en el que se critica el baile extático descontrolado, este pasaje no tiene por qué causar confusión o suponer una contradicción si se lee a la luz de la consideración platónica del simposio filosófico, de la poesía lírica arcaica (ditirámbica) o de los misterios dionisíacos que se han mostrado hasta ahora. A eso se añade el hecho de que la embriaguez moderada era un lugar común de la filosofía griega y la retórica ${ }^{26}$. El pasaje siguiente 
muestra, a mi parecer, que Dioniso entra de lleno en el proyecto pedagógico y político de las Leyes de Platón ${ }^{27}$. Lo más interesante es constatar el uso del vino como auténtico phármakon político y educativo, en las tres categorías bajo el dominio del dios: simposio, misterios y poesía. Pero, siguiendo la vieja y buena ley del pseudoplatónico Minos que se citaba, esto solo se logrará si el líder del banquete hace observar las estrictas disposiciones para el uso adecuado del vino. El extranjero ateniense distingue tres categorías en la regulación del uso del vino. Hasta 18 años hay una prohibición absoluta de probar el vino, a partir del 30 comienza el disfrute moderado y a partir de los cuarenta, se puede incurrir al fin en la embriaguez dionisíaca (Leyes 666a-c).

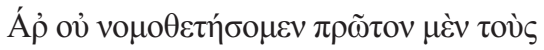

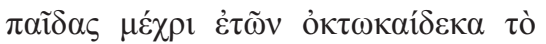

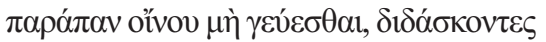

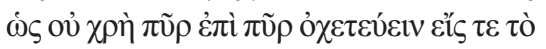

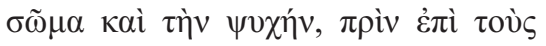

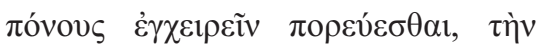

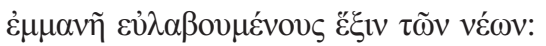

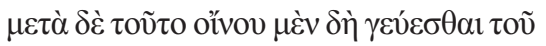

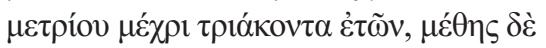

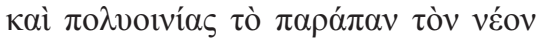

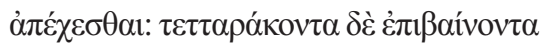

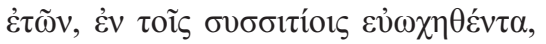

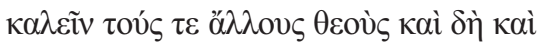

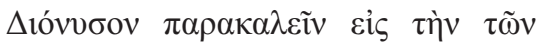

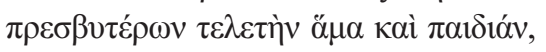

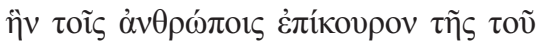

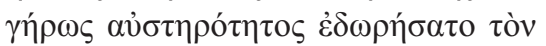

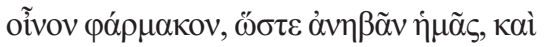

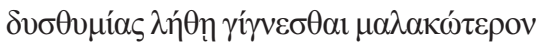

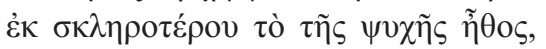

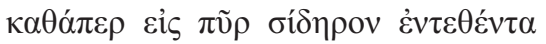

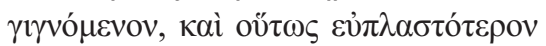

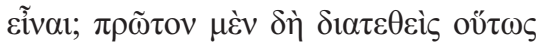

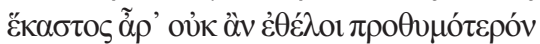

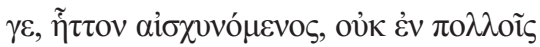

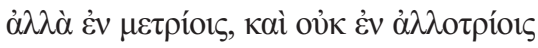

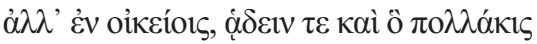

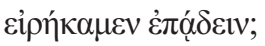

¿Acaso no hemos de legislar primero que los niños hasta los dieciocho años no prueben el vino en absoluto, enseñándoles que no conviene echar fuego sobre fuego en el cuerpo y en el alma, antes de emprender las fatigas del trabajo, por comportarse los jóvenes como locos? ¿Después de esto que disfruten del vino con mesura hasta los treinta años, pero absteniéndose el joven totalmente de incurrir en la embriaguez y la abundancia de vino? ¿Y cuando llegue a los cuarenta que, tras haberse alimentado suficientemente en las comidas en común, invoque también a los otros dioses y sobre todo que convoque a Dioniso al misterio de los más ancianos, que es al mismo tiempo juego, por el que regaló los hombres como ayudante de la seriedad de la vejez el vino como remedio, de forma que rejuvenezcamos y que con el olvido del mal ánimo el carácter del alma, a partir de la mayor dureza, se ablande, como le ocurre al hierro expuesto al fuego, para ser más fácil de moldear? Primero, el que haya atravesado esta experiencia, ¿no estaría dispuesto a entonar canciones con mejor ánimo no delante de muchos sino ante un número mesurado y no entre extraños sino entre los amigos y también, como dijimos muy a menudo, encantos?

Una vez más, el tema que aparece en el trasfondo recuerda al mito religioso de 
las distintas edades humanas en relación con Dioniso. Pero las reglas del vino no sólo recuerdan la clasificación de las edades de Hesíodo, sino también a las distintas etapas de los misterios y a sus iniciaciones, según las cuales las almas de los iniciados deben avanzar por grupos de edad y experiencia hasta llegar a las islas de los bienaventurados. De acuerdo con Morrow, el regalo de Dioniso no es realmente dañino para la ciudad, sino beneficioso cuando se usa correctamente, pero "el uso del vino no debe ser considerado como un mero divertimento para ser disfrutado por cualquier persona, con cualquier persona o de cualquier manera en que se desee, sino que debe estar asociado siempre a la ley y dirigido a la finalidad de obtener templanza." ${ }^{28}$ En efecto, en las Leyes la embriaguez se contempla solo si está bien regulada ${ }^{29}$. En los dos primeros libros de las Leyes se pondera el valor potencialmente educativo del simposio, pero alguien siempre debe estar al mando y controlándolo (640a), como en la propia ciudad, mediante la ley. El líder debe permanecer sobrio y ser mayor que los demás participantes, como muestra la edad provecta de los dirigentes del estado que propone Platón en las Leyes y la propia formación de un coro de ancianos dedicado a Dioniso. El simposio dionisíaco parece, en efecto, una miniatura de la polis $\mathrm{y}$, como dice Rinella: "La institucion del beber regladamente en las Leyes es un constructo utópico como todo lo que se encuentra en el estado ideal de la República, o como el relato santificado del simposio en el Banquete" ${ }^{\text {" }}$. Pero lo verdaderamente notable es que Platón elabora un programa educativo en el que Dioniso tiene un importante papel y utiliza la embriaguez como parte de su esfuerzo para reordenar el simposio, es decir, la política ateniense, con el objetivo de crear una educacion moral. Cito de nuevo a Rinella, "Platón subsume el lenguaje, ritual y experiencia extática de la intoxicación (methe) que se encuentra en el simposio en sus planes para un nuevo sistema de enculturación (paideia), de una manera muy similar a la forma en que subsume el lenguaje, ritual y experiencias extáticas de los misterios eleusinos ${ }^{\text {“31 }}$. La experiencia del éxtasis queda racionalizada y el vino se vuelve un tipo de remedio para la rigidez mental, un phármakon para la convivencia política.

Otra reciente interpretación del diálogo ha subrayado la relación de este tema con lo dionisíaco, esta vez a raíz de la mencionada cita de $817 \mathrm{~b}$, que compara la obra del legislador con una tragedia y al nomothetes con un poietés. Giovanni Panno estudia los elementos trágicos y dionisíacos en las Leyes, comparándolas con las Bacantes de Eurípides $^{32}$. Este autor identifica elementos simbólicos del teatro en las Leyes, que dejan que las contradicciones sociales y psicológicas lleven a la crisis de lo político y a la catarsis que supone este nuevo sistema y compara la legislación de Magnesia con el dionisismo y Dioniso, el dios que sufre y se acerca a los humanos, entendido como símbolo de la alteridad. En ese sentido se interpretan los famosos pasajes de la marioneta humana regida por diversos impulsos (644e-645c).

Me acerco ya a las conclusiones provisionales de este sucinto panorama sobre el dios de la máscara en Platón. En comparación con otras obras del filósofo, se diría que Dioniso es uno de los más im- 
portantes dioses en el sistema de educación religiosa de la ciudad ideal de Magnesia. En las otras obras de Platón, la presencia del dios se deja intuir en varios detalles y alusiones, en presencias o ausencias, que aluden a los tres mencionados campos semánticos bajo el patrocinio de esta divinidad que se han repasado brevemente en lo que no pretende ser sino una invitación a un trabajo más detallado sobre el dionisismo en Platón. Sin embargo, en las Leyes, con las que concluirán estas reflexiones, la presencia de este dios es abrumadora. El objetivo principal del diálogo es asegurar unas herramientas legales lo más perfectas posible y lo más cercanas al modelo de la ley divina de la edad áurea (713) y que los futuros ciudadanos tengan una educación adecuada y una sensibilidad real de la ley y la sociedad en que viven. Y en ello resulta fundamental la vertiente política de Dioniso. En el libro II el coro, entendido como educación musical y a la vez moral, ha de garantizar que niños, adolescentes y adultos, aprendan a sentir dolor y alegría en las ocasiones adecuadas. La educación religiosa es una parte esencial de este proceso sociopolítico, tanto en la infancia y en la edad adulta como en la vejez.

En el diálogo, a partir de las fiestas religiosas de Apolo, Dioniso y las Musas $(653 \mathrm{~cd})$, se establecen tres coros regentados por cada una de estas figuras mitológicas. Y puesto que Dioniso es el gobernante del coro de ancianos, será el dios que más influencia tenga sobre la clase gobernante de la ciudad. El extranjero dice al final del libro II que no se deberia culpar al don de Dioniso de los males de la ciudad (672a) y queda claro que el vino es una medicina, un phármakon concedido por los dioses. Es a partir de los cuarenta años cuando el hombre debe darse especialmente a las comidas comunes e invocar la presencia de Dioniso en este juego educativo, en este rito mistérico de hombres maduros, pues parece una medicina que el dios ha dado para los rigores y durezas de la edad adulta (666b). Estos coros de ciudadanos desempeñan un papel simbólico y casi mágico en la educación, porque tienen que mantener una especie de encanto sobre las almas de los ciudadanos (664b-665c) en toda la ciudad. Han de procurar el estado de ánimo preciso para que prevalezca el encanto de la ley.

Es significativo observar cómo las personas de edad participan plenamente de la embriaguez dionisíaca, de sus misterios y de su lírica, pero a la vez también de una plena responsabilidad del gobierno y de un ascendente moral sobre la educación de la sociedad. Es interesante cómo se inserta aquí Dioniso, con su plena y potente epifanía de la danza, la lírica antigua y la música, pero también con el vino y los misterios, en el sistema político ideal propuesto por Platón, condicionado siempre por su proyecto pedagógico. En ese sentido estoy de acuerdo con Wildberg en que, tras revisar los motivos dionisíacos en Platón, salta a la vista que su principal preocupación es, como un filósofo político, hallar la manera de integrar sus símbolos y funciones en el discurso de su nueva polis reformada y proyectada, en paralelo al esfuerzo de la propia democracia ateniense para "domesticar" el culto de Dioniso ${ }^{33}$. Pero no creo que este pasaje del coro de Dioniso se limite a regular las condiciones de culto religioso para el sim- 
posio ritual ${ }^{34}$, sino que tiene una intencionalidad pedagógica y política muy relevante, que va más allá de su mera integración en la polis, para convertir al dios de la máscara, en sus tres facetas aludidas -misterios, simposio y poesía como educación del alma- en una divinidad hondamente enraizada ya y altamente simbólica para la psicología platónica. Tal vez el mismo Platón hubiera sido en sus últimos años un fiel servidor del dios del éxtasis y de los simposios mistéricos característicos de la edad de oro. Pero ¿cómo se explica la aparente contradicción entre las Leyes y de la $R e$ pública, donde Dioniso nunca fue mencionado? Como ya hemos visto, también en la República hay un coro anónimo de Dioniso intuido en la mención del ditirambo. Me gustaría mencionar, para terminar, que tampoco se menciona positivamente el teatro en las Leyes, pues su función educativa en la democracia ateniense no podía hacerlo aceptable para Platón. El enfoque de la educación de la ciudad ideal de Platón está más bien en el

\section{BIBLIOGRAFÍA}

Anderson, D. (1993), The Masks of Dionysos: A Commentary on Plato's Symposium, Albany, NY, State University of New York Press.

Anton, J.P, (1962) 'Some Dionysian References in the Platonic Dialogues," The Classical Journal, 58, 49-55.

Detienne, M. (1977) Dionysos mis à mort, Paris: Gallimard.

Belfiore, E. (1986), "Wine and Catharsis of the Emotions in Plato's Laws," The Classical Quarterly 36, 421-37. coro, en la lírica coral, arcaica, aristocrática, prestigiosa y prodoria (seguramente sea posible situar a Platón en la tradición de las facciones más o menos confesadamente prolacedemonias de la sociedad ateniense). No hay teatro, pero la propia ley de la ciudad es la poesía dramática y Dioniso está todavía allí, como en la República. Cuando se habla de los diferentes tipos de música y de la poesía mejor, la inmutable y tradicional en las Leyes, se menciona "el 1lamado ditirambo, una invención, creo yo, de Dioniso" (700b). La ley encanta gracias a los preámbulos de Dioniso y sus coros que representa el bueno y antiguo nomos. En paralelo, la República (394c) presentaba el ditirambo como ejemplo de poesía narrativa en la que el poeta, como un legislador, es el único que habla, bajo el influjo del dios de la inspiración poética. La gran diferencia es que en las Leyes el coro dionisíaco no lleva máscara, como en los diálogos anteriores de Platón, y deja sentir toda su fuerza poética para la cohesión sociopolítica de la ciudad.

Boyancé, P. (1951), "Platon et le vin”, Bulletin de l'Association Guillame Budé, décembre, 4, 3-19.

Brunet, R. (1990), "Vin et philosophie: le Banquet de Platon; esquisse d'une sympotique platonicienne", en G. Garrier (dir.), Le vin des historiens : actes du ler Symposium Vin et Histoire : 19, 20 et 21 mai 1989, 1990, ISBN 2-85744-466-X, págs. 21-48.

Clark, R.B. (2003), The Law Most Beautiful and Best: Medical Argument and Magical Rhetoric in Plato's Laws. Lanham, MD: Lexington Books. 
David, E. (1978), "The Spartan Syssitia and Plato's Laws", The American Journal of Philology, Vol. 99, No. 4., 486-495.

Destrée, P. y Herrmann, F.-G. (ed. 2011), Plato and the Poets. Mnemosyne supplements. Monographs on Greek and Latin language and literature, 328. Leiden; Boston: Brill.

Girard, R. (1972). La Violence et le Sacré. Paris, Grasset.

Hernández de la Fuente, D. (2009), “La edad de oro dionisíaca: una utopía entre religión y política", Quaderni del Dipartimento di Filologia Linguistica e Tradizione Classica "Augusto Rostagni” dell'Università di Torino 8, 97-116.

Jeanmaire, H. (1951), Dionysos: histoire du culte de Bacchus, Payot, París.

Kerényi, K. (1976), Dionysos. Urbild des unzerstörbaren Lebens, Munich [trad.ing. Princeton: Princeton University Press; trad. esp. Barcelona: Herder, 1994].

Morrow, G.R. (1960): Plato's Cretan City: A Historical Interpretation of the Laws. Princeton: Princeton University Press. Otto, W. (1933), Dionysos: Mythos und Kultus, Frankfurt, V. Klostermann [trad. esp. Madrid, Siruela 1997].

Panno, G. (2007), Dionisiaco e Alterità nelle "Leggi" di Platone. Ordine del corpo e auto-movimento dell'anima nella città-tragedia. Milano: Vita e Pensiero.
Pradeau, J.F. (2004), 'L'ébriété démocratique. La critique platonicienne de la démocratie dans les Lois“", Journal of Hellenic Studies, 124, 108-124.

Henrichs, A. (1978), "Greek Maenadism from Olympias to Messalina”, Harvard Studies in Classical Philology 82, 121-160.

Rapp, A. (1872), “Die Mänade im griechischen Cultus, in der Kunst und Poesie", Rheinisches Museum für Philologie 27.

Rinella, Michael A. (2010), Pharmakon: Plato, Drug Culture, and Identity in Ancient Athens. Lanham, MD: Lexington Books. Robins, E. (1883), "Maenadism in Religion," Atlantic Monthly, Vol. LII, 487-497.

Seaford, R. (2006). Dionysos. Londres, Nueva York: Routledge.

Sider, D. (1980), "Plato's Symposium as Dionysian festival", Quaderni Urbinati di Cultura Classica 33, 41-56.

Vicaire, P. (1958) "Platon et Dionysos", Bulletin de l'Association Guillaume Budé, 15-26.

Tecusan, M. (1990), 'Logos Sympotikos: Patterns of the Irrational in Philosophical Drinking: Plato Outside the Symposium," O. Murray (ed.) Sympotica: A Symposium on the Symposion, Clarendon Press: Oxford, 238-262.

Wildberg, C. (2011), "Dionysus in the Mirror of Philosophy: Heraclitus, Plato, Plotinus" in R. Schlesier, Dionysos: A Different God?, Berlin, 205-232.
${ }^{1}$ Sobre el menadismo, cf. el viejo estudio de Rapp 1872, y la visión comparada con otras religiones -ciertamente anticuada- de Robins 1883, que luego sería estudiada más modernamente por Dodds 1951. Cf. también un recorrido sobre el menadismo griego y su recepción por Henrichs 1978.

${ }^{2}$ Cf. en general. Henrichs 1978.

${ }^{3}$ Las contribuciones más relevantes sobre los di- versos aspectos de Dioniso en la obra de Platón son, a nuestro ver, Boyancé 1951, Vicaire 1958, 15-16, Anton 1962, Brunet 1990, 21-48, Tecusan 1990, Anderson 1993, Panno 2007 y Wildberg 2011. Esta contribución las tiene en cuenta y, además, recoge y desarrolla las tesis sostenidas en un artículo del autor publicado en la Zeitschrift für Religions- und Geistesgeschichte 65.1 (2013). 
${ }^{4}$ P.e. Rep. 363c. Cf también el tratamiento de la danza extática en Leyes $815 \mathrm{c}$ o en la Carta VII, cuando un supuesto Platón habla de los sicilianos.

${ }^{5}$ Jeanmaire 1951, 5 y 35.

${ }^{6}$ Traducción M. Martínez, en Platón, Fedón, Banquete, Fedro, traducciones, introducciones y notas por C. García Gual, M. Martínez Hernández y E. Lledó Íñigo, Madrid, Gredos (BCG 93), 1986.

${ }^{7}$ Cf. Anton, 1962, Sider 1980.

${ }^{8}$ Anderson 1993, 7-8.

${ }^{9}$ Wildberg 2011, 218-220, que destaca el uso de imaginería dionisíaca para Sócrates. Tal vez como un nuevo Dioniso filosófico en su faceta de simposiarca

${ }^{10}$ Traducción E. Lledó, en Platón, Fedón, Banquete, Fedro, traducciones, introducciones y notas por C. García Gual, M. Martínez Hernández y E. Lledó Ínigo, Madrid, Gredos (BCG 93), 1986.

${ }^{11}$ Traducción de E. Lledó en Platón, Diálogos I. Apología, Critón, Eutifrón, Ion, Lisis, Cármides, Hipias Menor, Hipias Mayor, Laques, Protágoras. Edición general: E.Lledó Íñigo. Traducción y notas: J. Calonge Ruiz, E. Lledó Íñigo y C. García Gual. Ed. Gredos Madrid (BCG 37), 1985.

${ }^{12}$ Cf. también Fedro 245a, Banquete 209a, Rep. 398a, Leyes 817 b-d.

${ }^{13}$ Vicaire 1958, 20-21.

${ }^{14}$ Traducción de procedente de Platón, La República. Traducción de Rosa M Mariño Sánchez-Elvira, Salvador Mas Torres y Fernando García Romero, Akal, Madrid, 2009.
${ }^{15}$ Aristóteles, Probl. XIX 15 918. Cf. con un Ditirambo mimético de Píndaro (Frag. 74).

${ }^{16}$ Aristóteles, Poética 1449a10-15.

${ }^{17}$ David 1978.

${ }^{18}$ Texto de Platonis Opera, ed. John Burnet. Oxford University Press. 1903.

${ }^{19}$ Léase para la traducción $\tau \dot{\alpha} \pi \mathrm{o} \lambda \lambda \dot{\alpha}$, siguiendo la edición Aldina de las Leyes, en vez de $\kappa \alpha \tau \grave{\alpha} \pi \mathrm{o} \lambda \lambda \grave{\alpha}$, lectura de la tradición manuscrita recogida por Burnet, en este sentido

${ }^{20}$ Hernández de la Fuente 2009.

${ }^{21}$ Plutarco, De Is. et Os. 35.: "señor de todo elemento húmedo".

${ }^{22}$ Platón, Ion 534a.

${ }^{23}$ Traducción de F. Lisi 1999a, 370.

${ }^{24}$ Belfiore 1986.

${ }^{25}$ Cf. Belfiore 1986, 421-437 y Pradeau 2004, 4367.

${ }^{26}$ Según Bertrand 2004, 33-41.

${ }^{27}$ Hay diversas interpretaciones, Boyancé 1951, 3 19, Morrow 1960, 441-443, Brunet 1990, 21-48, Tecusan 1990, 238-262.

${ }^{28}$ Morrow 1960, 441-3. Mi traducción.

${ }^{29}$ Rinella 2010, 57, Clark 2003, 140.

${ }^{30}$ Rinella 2010, 61-62. Mi traducción.

${ }^{31}$ Rinella, ibid. Mi traducción.

32 Panno 2007.

${ }^{33}$ Wildberg 2011, 218.

${ }^{34}$ Wildberg 2011, 223. 